\title{
The Correlation Analysis between Bullying and Experiences in Close Relationships in High School Students
}

\author{
Sevda Aslan\#,*
}

Kırıkkale University, Education Faculty, Educational Sciences Department, Kirikkale, Turkey

\begin{abstract}
In this study, it is aimed to determine whether there is correlation between the school bullying and the experiences of adolescents in their close relationships. The participants of this study consisted of children from 9th,10th,11th,12th grades of three different high schools. In this research, Student Relationships Attitude Scale and Experiences in Close Relationships Inventory were used as data collection tools. Results of the study revealed significant positive relationships between the bullying personality attitude and attachment avoidance and attachment worry dimensions of the Experiences in Close Relationships Inventory. Significant relationships were found between confident attitude and attachment avoidance dimension of the Experiences in Close Relationships Inventory.
\end{abstract}

Keywords: Adolescent, close relationships, school bullying.

\section{INTRODUCTION}

Adolescence is another intense period after puberty in which physical, personal, social and mental changes are experienced. From this perspective, an individual is expected to become an adult by both adapting to his changing body and to his identity development. On his way to adulthood, an adolescent gains experience which helps him to develop primarily by means of the relationships he builds up with his peers. School is the main place where an adolescent spends time with his peers. Individuals from different cultures, family circles and socio-economic situations bring about an education atmosphere.

According to Olweus (1993), the most bullying incidents are experienced in schools because they are from different social environments. School bullying generally aims only at students. Younger and weaker students report that they have been bullied more. Direct bullying is attacking victims openly, whereas indirect bullying is excluding a victim in a group on purpose and applying social isolation. However, this type of bullying is not very common. Girls suffer from indirect bullying as much as boys. Both girls and boys report that they have been bullied more in the early years of high school compared with the following years. Bully boys are especially physically stronger than their victims. Bullying and being a victim go on for a long time. It is a slight possibility for a victim to get rid of

*Address correspondence to this author at the Faculty of Educational Sciences, Psychological Counselling and Guidance Department, University of Kırıkkale, Ankara Road 7.km, 71450 Yahşihan/Kırıkkale, Turkey; Tel: +90 505791 2371; Fax: +90 318357 2487; E-mail: sevda.aslan@gmail.com,

sevda.aslan@kku.edu.tr

"Dr. Sevda ASLAN is an Associate Professor Doctor at the Faculty of Education, Psychological Counselling and Guidance Department, University of Kırıkkale. Her research focuses on separation-individuation during adolescence with a special interest in school as a developmental context. being bullied unless $s /$ he changes the conditions effectively. Besides this, bullying incidents continuing for a long time cause bullying to continue even for a longer time as a stimulating factor. What is more, victims feel worried and insecure and they evaluate themselves negatively. These conditions also cause them to be continuously bullied by their peers.

When viewed from gender perspective, boys are stiffer, tougher and more aggressive than girls (Macobby, 1986: Cited in., Olweus 1993). Social, biological and environmental factors play an important role in these differences between girls and boys (Olweus 1993). It was put forward that peer bullies experience worry and insecurity and they also have low self-respect (Olweus 1994). On the other hand, it was observed that victims feel more worried and insecure than the other students. These students are forsaken and alone at school. Passive victims feel insecure and worthless when they are disdained, insulted or attacked and display these feelings to others with their attitudes and behaviours. These victims are worried or meek as well as being physically weak. Meanwhile, bullies behave aggressively towards their peers and adults. They also exhibit a positive attitude by exerting violence towards their peers. Bullies empathise their victims only a little (Olweus 1973a and 1978; Björkvist et al. 1982; Lagerspetz et al. 1982: Cited in. Olweus 1993). Peer bullies feel in need of power and domination. When they grow up, bullies have the feeling of enmity at certain levels towards their surroundings. They are able to achieve satisfaction without hurting other individuals with the help of their instincts and feeling of enmity (Olweus 1993).

When the relevant literature was consulted, it was observed that the following issues were mentioned; 
- children who are bullied usually experience worry (Kochenderfer-Ladd and Skinner 2002)

- depression (Austin and Joseph, 1996; Juvonen, Adrienne and Graham 2000)

- social withdrawal (Schwartz, Dodge and Coie 1993; Boivin, Hymel and Bukowski 1995)

- loneliness (Boivin, Hymel and Bukowski 1995; Boulton and Underwood 1992)

- $\quad$ peer rejection behaviours (Perry, Kusel and Perry 1988)

- the relationship between peer bullying and guilt (Baldry ve Farrington 2000)

In this study, it is aimed to analyze the relationship between school bullying and the experiences of adolescents in their close relationships in order to better explain the concept of school bullying and also to contribute to the relevant culture.

\section{METHOD}

\subsection{Study Group}

The study group consisted of 408 participants aged between 15-18 studying at Kanuni High School, Fatih Sultan Mehmet High School and Çubuk Health Professions High School. They were 9th, 10th, 11th and 12th grade students continuing their education during the spring semester of 2009-2010. However, the data gathered from 14 students was excluded from the study since it was incomplete and there were incorrect markings on the form. Therefore, the data analysis was conducted out of a 394-student data set. The study group consisted of $254(64.5 \%)$ female students and $140(35.5 \%)$ male students.

\section{Data Collection Tools}

In this study, "Student Relationships Attitude Scale", "Experiences in Close Relationships Inventory and "Personal Information Form", which were all developed for this study, were used as data collection tools.

Developed by Koç (2006), Student Relationships Attitude Scale is a self administered dimensional questionnaire constructed to assess the bullying personality, self confidence and avoidance from bullying of relationship attitudes. Student Relationships Attitude Scale is a 5-point Likert-type scale composed of 21 items. Bullying personality, one of the subscales, is a personality which displays the attitudes and behaviours such as gossiping, teasing, social exclusion, all kinds of verbal or physical violence, threatening, experiencing worry without a reason or showing aggression towards the victim when s/he is in trouble. On the other hand, avoidance from bullying subscale is avoiding from these kinds of attitudes and behaviours such as gossiping, teasing, social exclusion, all kinds of verbal or physical violence, threatening. Also, self confidence subscale is described as being confident of interpersonal relationship. Aggression Inventory developed by Tuzgöl (1998) was used in order to determine the criterion validity of the scale. It was found that there was .60 correlation for bullying personality subscale, .41 correlation for selfconfidence subscale and .60 correlation for avoidance from bullying subscale of the Student Relationships Attitude Scale with the Aggression Inventory. As a result of the factor analysis done in the construct validity work, it was found that factor loads of the subscales differ between .51 and .75. The variance explained by the three factors which comply with the theoretical structure of the scale was found to be $43 \%$. The Cronbach Alpha of the subscales of Student Relationships Attitude Scale was found .86 for bullying personality, .69 for self-confidence and .57 for avoidance from bullying.

"Experiences in Close Relationships Inventory" was developed by Brennan et al. (1998) and was adapted by Sumer and Gungor (2000) for Turkish high school students. Experiences in Close Relationships Inventory measures attachment avoidance and attachment anxiety with romantic partners. the Experiences in Close Relationships Inventory is a 4-point Likert type scale composed of 36 items independent from each other. The Cronbach Alpha of Experiences in Close Relationships Inventory was found .81 for avoidance and .84 for worry (Cited in., Gungor 2000).

\subsection{Process}

Before administration of the scales, appointments were arranged with the class instructors at Kanuni High School, Fatih Sultan Mehmet High School and Çubuk Health Professions High School. The purpose of the study was explained to them, and their permission was sought to apply the instruments during their classes. After obtaining their approval, the researchers applied the instruments on the participants who had volunteered. Before administration, informed consent and permission to report the findings were obtained from the volunteer participants. During the 
administration, the participants were also informed about the purpose and completion of the study, and were assured about the anonymity and confidentiality of their responses. Correlation techniques were utilized in the statistical analysis of the data.

\section{FINDINGS}

The results of the Pearson's Product Moment Correlation Coefficient conducted between Student Relationships Attitude subscales and Experiences in Close Relationships Inventory are as follows: It was found that there is a positive correlation between the bullying personality subscale of Student Relationships Attitude Scale and attachment avoidance and worry dimensions of the Experiences in Close Relationships Inventory. While there was a positive correlation between self confidence subscale of the Student Relationships Attitude Scale and attachment avoidance dimension of the Experiences in Close Relationships Inventory, there was no significant correlation with the attachment worry dimension. There was a positive correlation between the avoidance from bullying subscale of Student Relationships Attitude Scale and the attachment avoidance dimension of the Experiences in Close Relationships Inventory; however, there was no significant relationship with the attachment worry dimension.

\section{DISCUSSION AND COMMENT}

In conclusion, there was a positive correlation between the bullying personality subscale of Student Relationships Attitude Scale and the attachment avoidance and attachment worry dimensions of the Experiences in Close Relationships Inventory. It was found that there was a positive correlation between the subscales of self-confidence, avoidance from bullying and the attachment avoidance dimension of the Experiences in Close Relationships Inventory. However, there was no significant relationship between the attachment worry dimension of the Experiences in Close Relationships Inventory and the subscales of self-confidence and avoidance from bullying.

Bully person in Student Relationships Attitude Scale is described as a personality who display the attitudes and behaviours such as gossiping, teasing, social exclusion, all kinds of verbal or physical violence, threatening, experiencing worry without a reason or showing aggression towards the innocent and desperate victim when s/he is in trouble. It can be said that the fact that there is a positive correlation in attachment worry and avoidance dimensions in the adolescents' experiences with the individuals who have these kinds of attitudes show that adolescents experience worry during the relationships with the individuals who display bullying attitudes and therefore they try to avoid from these type of individuals. Avoidance from bullying subscale is avoiding from displaying these behaviours and attitudes. It can be said that it is an acceptable result for this subscale to display a significant relationship with the attachment avoidance dimension of the Experiences in Close Relationships Inventory.

In this study, self-confidence subscale of the Student Relationships Attitude Scale displays a differentiation with the attachment avoidance dimension of the Experiences in Close Relationships Inventory. It can be said that it is an acceptable result for adolescents who perceive themselves in a safe way in the relationships with their peers prefer avoidance rather than experiencing negative attitudes in their close relationships. The result that there is no significant relationship between the attachment worry dimension of the Experiences in Close Relationships Inventory and self-confidence, avoidance from bullying subscales of the Student Relationships Attitude Scale can be examined through research to be done with different sample groups and it can be analyzed whether the results will fortify the results of this study.

A limitation of this study is the fact that it has been conducted only with high school students. Therefore, further research can be done in which individuals from different socioeconomic levels are included in order to investigate the correlation bullying and close relationships. Further research can be carried out whether similar findings regarding bullying and close relationships will be demonstrated by conducting longitudinal studies in future.

\section{REFERENCES}

Austin, Sharon and Stephen Joseph 1996. "Assessment of Bully/Victim Problems in 8 to 11 Year Olds." British Journal of Educational Psychology 66:447-456. http://dx.doi.org/10.1111/j.2044-8279.1996.tb01211.x

Baldry, Anna C. and David P. Farrington 2000. "Bullies and Delinquents: Personal Characteristics and Parental Styles." Journal of Community \& Applied Social Psychology 10:1731.

http://dx.doi.org/10.1002/(SICl)10991298(200001/02)10:1<17::AID-CASP $526>3.0$. CO;2-M

Boivin, Michel, Shelley Hymel, and William M. Bukowski 1995. "The Roles of Social Withdrawal, Peer Rejection, and Victimization by Peers in Predicting Loneliness and Depressed Mood in Childhood." Developmental and Psychopathology 7:765-785. http://dx.doi.org/10.1017/S0954579400006830 
Boulton, Michael J. and Kerry Underwood 1992. "Bully/Victim Problems among Middle School Children." British Journal of Educational Psychology 62:73-87. http://dx.doi.org/10.1111/j.2044-8279.1992.tb01000.x

Brennan, Kelly A., Catherine L. Clark, and Phillip R. Shaver 1998. "Self-Report Measurement of Adult Attachment: An Integrative Overview." Pp. 46-76 in Attachment Theory and Close Relationships, edited by J. A. Simpson and W. S. Rholes, New York: Guilford.

Gungor, Deniz 2000. "Bağlanma Stillerinin ve Zihinsel Modellerin Kuşaklararası Aktarımında

Anababalık Stillerinin Önemi [The Role of Parenting Styles in the Intergenerational Transmission of Attachment Styles and Mental Models]". PhD dissertation, Department of Psychology, University of Ankara, Ankara.

Juvonen, Jaana, Nishina Adrienne, and Sandra Graham 2000. "Peer Harassment, Psychological Adjustment, and School Functioning in Early Adolescence." Journal of Educational Psychology 92:349-359. http://dx.doi.org/10.1037/0022-0663.92.2.349

Kochenderfer-Ladd, Becky and Karey Skinner 2002. "Children's Coping Strategies: Moderators of the Effects of Peer Victimization?" Developmental Psychology 38:267-278. http://dx.doi.org/10.1037/0012-1649.38.2.267
Koç, Zihni 2006 . "Lise Öğrencilerinin Zorbalık Düzeylerinin Yordanması [Regresment of High School Students' Bullying Level]". PhD dissertation, Department of Educational Sciences, University of Gazi, Ankara.

Olweus, Dan 1993. Bullying at School. Bodmin, Cornwall: Blackwell.

Olweus, Dan 1994. "Annotation: Bullying at School: Basic Facts and Effects of a School Based Intervention Program." Journal of Child Psychology and Psychiatry 35:1171-1190. http://dx.doi.org/10.1111/j.1469-7610.1994.tb01229.x

Perry, David G., Sara J. Kusel, and Louise C. Perry 1988. "Victims of Peer Aggression." Developmental Pscyhology 24:807-814. http://dx.doi.org/10.1037/0012-1649.24.6.807

Schwartz, David, Kenneth A. Dodge, and John D. Coie 1993. "The Emergence of Chronic Peer Victimization in Boys' Play Groups." Child Development 64:1755-1772. http://dx.doi.org/10.2307/1131467

Tuzgöl, Meliha 1998. "Ana-Baba Tutumları Farklı Lise Öğrencilerinin Saldırganlık Düzeylerinin Çeşitli Değişkenler Açısından Incelenmesi". MS thesis, Department of Educational Sciences, University of Hacettepe, Ankara.

(C) 2015 Sevda Aslan; Licensee Lifescience Global.

This is an open access article licensed under the terms of the Creative Commons Attribution Non-Commercial License (http://creativecommons.org/licenses/by-nc/3.0/) which permits unrestricted, non-commercial use, distribution and reproduction in any medium, provided the work is properly cited. 